\title{
Churchill regulates cell movement and mesoderm specification by repressing Nodal signaling Eric R Londin ${ }^{1,2}$, Laura Mentzer ${ }^{1}$ and Howard I Sirotkin*1
}

Address: ${ }^{1}$ Department of Neurobiology and Behavior, Stony Brook University Stony Brook, New York, USA and ${ }^{2}$ Graduate Program in Genetics, Stony Brook University Stony Brook, New York, USA

Email: Eric R Londin - Eric.Londin@stonybrook.edu; Laura Mentzer - lmentzer@hotmail.com; Howard I Sirotkin* - hsirotkin@sunysb.edu

* Corresponding author

Published: 2 November 2007

BMC Developmental Biology 2007, 7:120 doi:10.1/86/147I-213X-7-120

Received: 21 May 2007

Accepted: 2 November 2007

This article is available from: http://www.biomedcentral.com/I47I-2I3X/7//20

(C) 2007 Londin et al; licensee BioMed Central Ltd.

This is an Open Access article distributed under the terms of the Creative Commons Attribution License (http://creativecommons.org/licenses/by/2.0), which permits unrestricted use, distribution, and reproduction in any medium, provided the original work is properly cited.

\begin{abstract}
Background: Cell movements are essential to the determination of cell fates during development. The zinc-finger transcription factor, Churchill $(\mathrm{ChCh})$ has been proposed to regulate cell fate by regulating cell movements during gastrulation in the chick. However, the mechanism of action of $\mathrm{ChCh}$ is not understood.

Results: We demonstrate that $\mathrm{ChCh}$ acts to repress the response to Nodal-related signals in zebrafish. When $\mathrm{ChCh}$ function is abrogated the expression of mesodermal markers is enhanced while ectodermal markers are expressed at decreased levels. In cell transplant assays, we observed that $\mathrm{ChCh}$-deficient cells are more motile than wild-type cells. When placed in wild-type hosts, $\mathrm{ChCh}$-deficient cells often leave the epiblast, migrate to the germ ring and are later found in mesodermal structures. We demonstrate that both movement of $\mathrm{ChCh}$-compromised cells to the germ ring and acquisition of mesodermal character depend on the ability of the donor cells to respond to Nodal signals. Blocking Nodal signaling in the donor cells at the levels of Oep, Alk receptors or Fastl inhibited migration to the germ ring and mesodermal fate change in the donor cells. We also detect additional unusual movements of transplanted $\mathrm{ChCh}$-deficient cells which suggests that movement and acquisition of mesodermal character can be uncoupled. Finally, we demonstrate that $\mathrm{ChCh}$ is required to limit the transcriptional response to Nodal.

Conclusion: These data establish a broad role for $\mathrm{ChCh}$ in regulating both cell movement and Nodal signaling during early zebrafish development. We show that chch is required to limit mesodermal gene expression, inhibit Nodal-dependant movement of presumptive ectodermal cells and repress the transcriptional response to Nodal signaling. These findings reveal a dynamic role for chch in regulating cell movement and fate during early development.
\end{abstract}

\section{Background}

The establishment of the vertebrate body plan depends on a carefully orchestrated series of position-dependent cell interactions that determine the nature and proportion of cells that will populate each of the three germ layers. The movement of cells or their resistance to move, influences the inductive signals they will encounter. These signals initiate developmental programs that generate various differentiated cell types.

The series of dynamic cell movements during gastrulation positions cells to receive signals that will direct them to a 
given fate. In zebrafish, these movements include epiboly, internalization and convergence and extension movements. Epiboly is the process of spreading and thinning of the embryo during blastula and gastrula stages. Mesendodermal precursor cells are located at the margin in a thickened region termed the germ ring. These precursors are internalized resulting in the formation of an outer epiblast layer and inner hypoblast layer [1].

As the germ layers are specified, there is an antagonistic relationship between mesoderm and neural induction. Expansion of the mesoderm comes at the expense of the ectoderm; conversely, repression of mesoderm results in an expansion of the ectoderm [2-5]. FGF signaling has critical roles in specification and patterning of the mesoderm and neural ectoderm in mice, frogs, fish and the chick [6-14].

In many species, neural and mesoderm induction occur at similar times and in adjacent cell populations. How can FGF function in the seemingly contradictory roles as an inducer of mesoderm and neural tissue? One possibility is that different FGF effectors are present in the mesoderm and ectoderm to regulate its activity. One candidate FGF effector is the zinc finger transcription factor Churchill (chch) [15].

chch overexpression in Xenopus embryos results in suppression of the mesodermal marker brachyury [15]. Morpholino knockdown of chch in the chick epiblast results in inappropriate migration of epiblast cells through the primitive streak [15]. chch morpholino-injected cells emerged from the primitive streak and gave rise to paraxial mesoderm. This suggests that chch is required to limit ingression of the epiblast allowing those cells to become neural tissue. In addition, the chick experiments implicate Smad-interacting protein-1 (Sip1) as a direct target of chch and suggest that Sip1 is the major chch effector involved in blocking ingression of the epiblast [15].

Although the effect of chch in the assays in the frog and chick is the same (to limit mesoderm), the mechanisms of action in these two experiments likely differ. One difference is that cell movement is not thought to be required for mesoderm induction in the animal cap assay. The chick experiments do not address the question of whether the migration of chch-inhibited epiblast cells exposes them to mesoderm-inducing signals or whether they migrate because they have already acquired mesodermal properties. In order to elucidate the mechanisms of action of chch, we have undertaken a series of experiments to study the requirement for chch in the zebrafish and to address the roles of chch in cell migration and cell fate.
Here, we show that chch is required to limit mesodermal gene expression in zebrafish. During gastrulation, inhibition of chch results in an increase in transcript levels of mesodermal genes and a decrease in levels of ectodermal transcripts. In cell transplant experiments, cells with compromised chch activity are more motile than wild-type cells when transplanted to the epiblast of wild-type hosts. These cells leave the epiblast and migrate into the germ ring to acquire mesodermal cell fates. We found that both migration of chch-compromised donor cells and acquisition of mesodermal character depend on Nodal signaling. Finally, we demonstrate that $c h c h$ is required to repress the transcriptional response to Nodal signaling. Together, these findings demonstrate that chch regulates cell fate by limiting the response to Nodal signals.

\section{Results \\ chch inhibition produces axial and somite defects}

Zebrafish chch sequence was previously reported [15] but the zebrafish chch has not been further characterized. We have determined that like in the chick, zebrafish chch is regulated by FGF signaling, but unlike in the chick expression is widespread and not limited to the prospective neural plate [16]. To examine the function of chch in zebrafish, we inhibited chch activity with a morpholino directed against the translation start site and a dominantnegative mRNA. Microinjection of $c h c h$-ATGMO produces embryos with enlarged and misshapen somites (Fig. 1B). In addition, these embryos have a short body axis and poorly formed anterior neural structures (Fig. 1B).

Since chch functions as a transcriptional activator [15], we generated a dominant-negative construct by fusing the zebrafish chch coding sequence to the drosophila engrailed repressor domain (chch-EnR). Microinjection of chch-EnR mRNA pronounced a similar phenotype to the morpholino; highly disorganized somites, a wide notochord and short axis were observed (Fig. 1C). Taken together, these results demonstrate that chch is essential for proper formation of the body axis and suggest that chch deficiency may result in convergence extension defects.

\section{chch is not required for expression of dorsal mesodermal markers}

To determine if the axial defects observed in chch compromised embryos stems from dorsal mesodermal defects, we examined dorsal mesodermal markers during early gastrulation by in situ hybridization and real-time PCR following microinjection of chch-EnR mRNA. At this stage, both chordin (chd) and floating head ( $f l h)$ are expressed within the dorsal mesoderm. Following microinjection of chchEnR mRNA, neither marker showed altered expression by RNA in situ hybridization (Fig. 2A-D) or real-time PCR (Fig. 2O). Other organizer-specific markers such as noggin and goosecoid were also examined (data not shown) and 

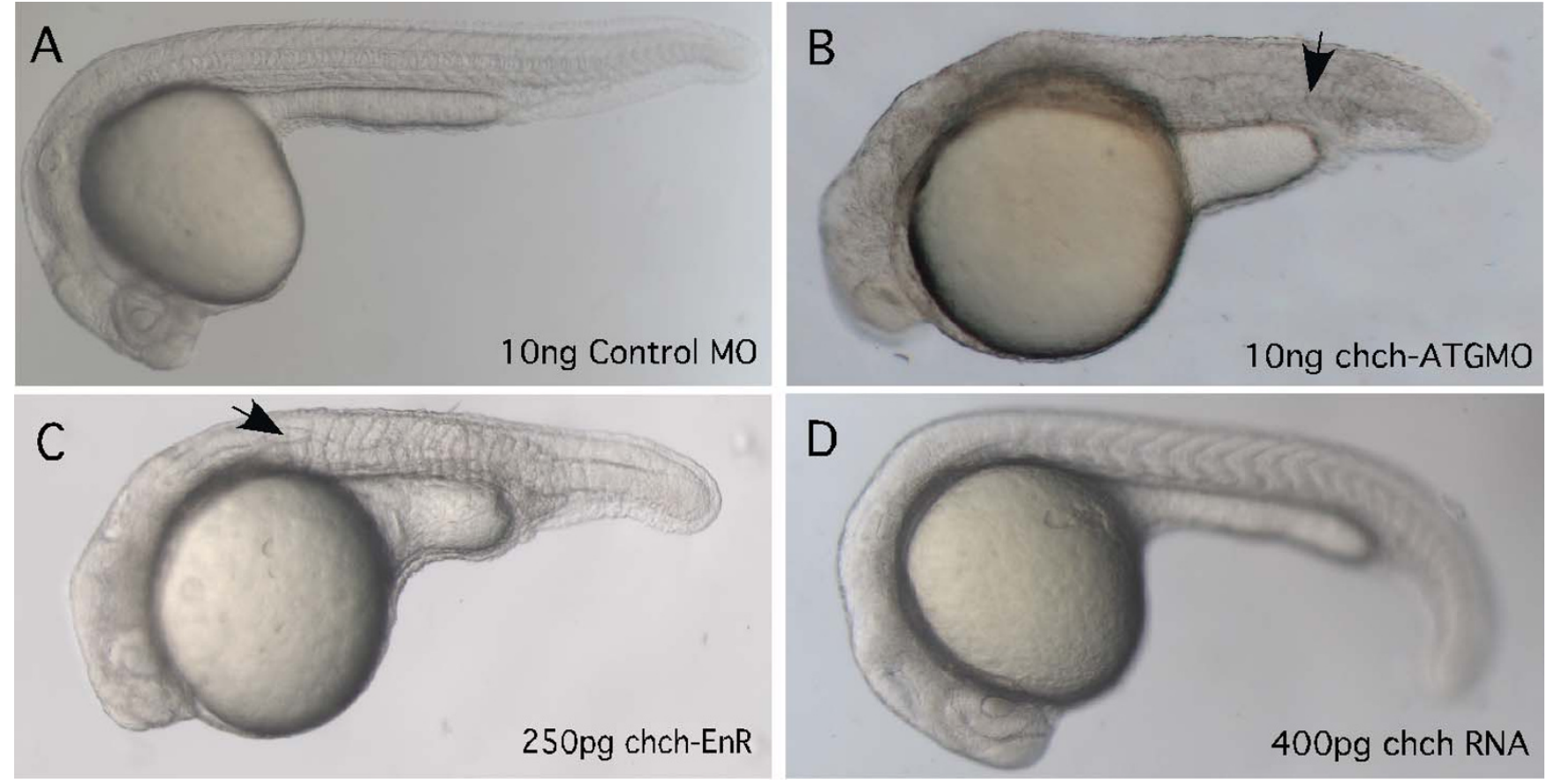

Figure I

chch inhibition results in axial and somite defects. The effect of inhibiting chch was examined using a morpholino and a dominant-negative construct. Microinjection of chch-ATGMO results in a broad, misshapen notochord (arrow) and misshapen somites and a shortened axis (B). Microinjection of chch-EnR, results in a similar phenotype as the morpholino, a broad, misshapen notochord, and enlarged and misshapen somites formed $(C)$. chch mRNA overexpression produces embryos that are wild-type in appearance (D). Arrowheads point to the notochord. All embryos are $24 \mathrm{hpf}$.

did not show a change in expression. Similarly, microinjection of chch-ATGMO did not produce changes in chd or flh expression by either in situ hybridization or real-time PCR (Fig. $2 \mathrm{O}$ and data not shown). These data suggests that repressing chch function does not alter initial specification of dorsal mesoderm but acts on subsequent steps in axial patterning or morphogenesis.

\section{chch regulates mesoderm specification}

To determine if expression of other mesodermal genes is altered when chch function is reduced, we examined panmesodermal markers at the start of gastrulation. In situ hybridization and real-time PCR were used to assay expression of no tail ( $n t l)$, spadetail $(s p t)$ and $t b x 6$. All of these markers showed significant increases in transcript levels at shield stage following microinjection of $c h c h$-EnR mRNA. When assayed by quantitative real-time PCR the mesodermal markers showed increases corresponding to as much as a to a 2-2.25-fold increase in transcript levels (Fig. 2O). The spatial alterations in gene expression were more subtle, as mesodermal markers showed slightly more robust expression (Fig. 2E-H and data not shown). Surprisingly, overexpression of chch mRNA did not alter mesodermal marker expression (Fig. 2I-J, O). Similarly, chch inhibition with the morpholino did not alter the spa- tial expression of mesodermal markers (data not shown) but slight increases in $n t l$ and spt gene expression were observed by real-time PCR (1.5 and 1.25-fold increases respectively, Fig. 2O). Importantly, co-expression of chchATGMO along with chch mRNA that had been mutated to prevent morpholino binding rescued the increases in mesodermal gene expression seen following chch inhibition (Fig. 2P). Together, these data demonstrate that chch is required to limit mesodermal gene expression. However, unlike in Xenopus [15], ectopic chch is insufficient to repress $n t l /$ brachyury expression.

Smad-interacting protein 1 (Sip1) is a direct target of chch in the chick [15] and a direct repressor of Xenopus brachyury [17]. Therefore, we asked whether the inability of ectopic zebrafish chch to repress $n t l$ stemmed from a failure to induce Sip1 expression. We examined Sip1 expression by real-time PCR with primers generated from the Sip1 genomic locus (Ensembl gene Id: ENSDARG00000059564) and by RNA in situ hybridization with a cDNA probe generated with primers designed from that locus. Overexpression of chch mRNA results in large increases in Sip 1 transcript levels when examined by RNA in situ hybridization (Fig 2L) and real-time PCR (Fig. $2 \mathrm{Q})$. Conversely, inhibition of $\mathrm{chch}$ with either the domi- 

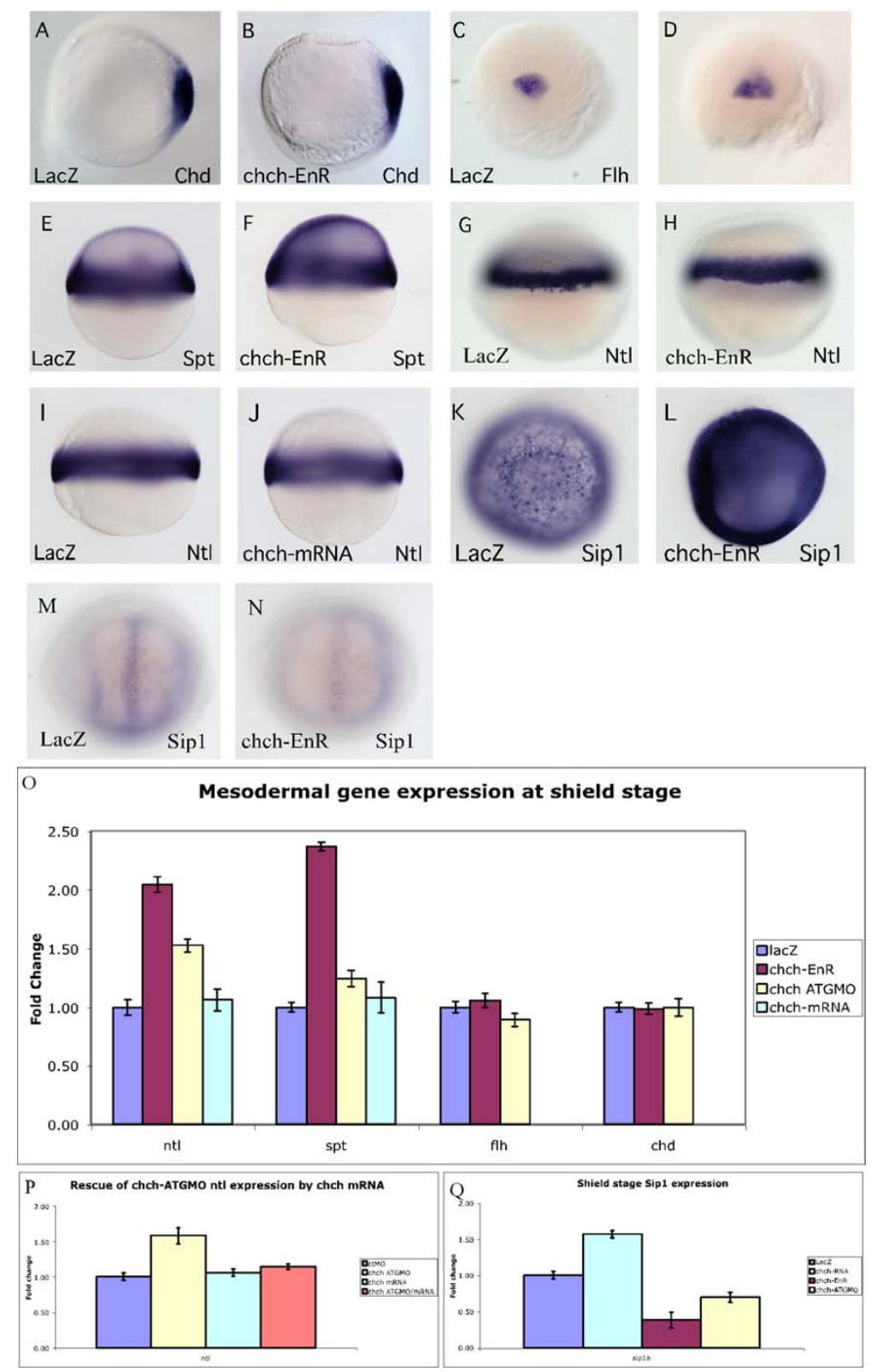

\section{Figure 2}

chch represses mesodermal markers. Mesodermal markers were examined by RNA in situ hybridization and real-time PCR in embryos microinjected with chch-EnR mRNA. Inhibition of chch does not alter expression of dorsal mesodermal genes chd (A, B) or flh (C, D). Expression of mesodermal markers at shield stage, including spt (E-F) and ntl (G-H) are expanded slightly in chch-inhibited embryos. Overexpression of chch mRNA does not alter no-tail expression at shield stage (I-J). chch inhibition results in a decrease in Sipl gene expression at bud stage (M-N), while chch activation results in Sip I induction at shield stage (K-L). Real-time PCR analysis of mesodermal markers in chch-inhibited embryos (O). The fold change in transcript levels (y-axis) is graphed relative to control embryos following overexpression of chch-EnR mRNA, chch-ATGMO and chch mRNA. This analysis reveals that the domains of mesodermal genes are expanded at shield stage while dorsal mesodermal genes are unaffected. Conversely, overexpression of chch mRNA does not result in alteration of early mesodermal gene expression. The induction of $n t l$ expression following chch inhibition with the ATGMO can be rescued by co-expression of chch mRNA (P).

Real-time PCR analysis of Sipl mRNA in chch, chch-EnR and chch-ATGMO treated embryos (Q). Induction of chch results in a $50 \%$ increase in Sipl expression, conversely, inhibition of chch results in a $70 \%$ reduction of Sipl expression. The fold change in Sip I transcript levels (y-axis) is graphed relative to control embryos. Views: A-B, K-L are animal pole; C-D, M-N are dorsal; E$\mathrm{J}$ are lateral. 
nant-negative construct (fig. $2 \mathrm{~N}$ and $2 \mathrm{Q}$ ) or the morpholino(Fig. 2Q) results in a decrease in Sip1 expression in the same assays. Together, these results reveal that zebrafish Sip1 is regulated by chch. Therefore, despite robust induction of Sip1, overexpression of zebrafish chch is not sufficient to alter $n t l$ expression.

We next assayed whether the increase in mesodermal gene expression following chch inhibition came at the expense of other germ layers. By late gastrulation, mesodermal markers in chch-inhibited embryos show a 50-75\% increase compared to control embryos when assayed by real-time PCR (Fig. 3A). Conversely, the endodermal markers, mixer and sox 17 , do not show altered mRNA levels at late gastrulation following inhibition of chch activity (Fig. 3A). This contrasts ectodermal gene expression at late gastrulation. By RNA in situ hybridization, the expression domains of the neural gene otx2 were not obviously altered (Fig. 3C-D) by late-gastrulation. However, realtime PCR analysis revealed that mRNA levels of both neural and epidermal markers were consistently decreased in chch morphants and chch-EnR treated embryos. The anterior neural marker ot 2 , the posterior neural marker hoxb1b, the pan-neural marker sox3 and the epidermal markers krt8 and gata2 all showed decreased transcript levels (Fig. 3B). By early somitogenesis, the anterior neural markers otx2 and six3 both had reduced expression domains in chch morphants (Fig. 3E-H). Overexpression of chch mRNA did not result in a change in ectodermal or endodermal gene expression during late gastrulation (data not shown).

While we observed a slight spatial increase in expression of mesodermal markers at shield stage when chch function was abrogated, we were unable to detect a subsequent spatial decrease in ectodermal marker expression until early somite stages. However, the quantitative real-time PCR data demonstrates a consistent decrease in the levels of expression of ectodermal markers during gastrulation. The ectodermal deficits may be too subtle to be detected by in situ hybridization. These findings suggest that $c h c h$ regulates mesodermal gene expression during early development.

\section{Inhibition of chch results in aberrant cell movements and cell fate changes}

We next examined whether repression of chch alters cell movements by tracking the behavior of chch compromised cells in a wild-type host. Sphere stage (mid-blastula) cells from ctMO or chch-ATGMO injected donor embryos were transplanted to the animal pole of similar stage wild-type hosts. Donor cell movements were observed at $40 \%$ epiboly, germ ring, shield stage and after 24 hpf (Fig. 4B-M). Control donor cells undergo limited movement and spreading (Fig. 4B-D). In contrast, chch- inhibited cells moved vegetally and spread much faster (Fig. 4F-H).

To determine whether the vegetal movement of chch inhibited cells resulted in a fate change, we recorded the position of the donor cells after $24 \mathrm{hpf}$. As expected, when transplanted to the animal pole, ctMO-donor cells generally became incorporated into anterior neural ectoderm (42/52 embryos 80.1\%, Table 1, Fig. 4E). In a few embryos, ctMO-donor cells were found in the superficial cell layers in 3/42 embryos (7.1\%, table 1$)$ or in both neural tissue and superficial cell layers of the trunk $7 / 52$ embryos (13.5\%, Table 1). chch morphant donor cells behaved differently (Fig. 4I, Table 1). When transplanted to the animal pole of a wild-type host, 44/72 embryos $(61.1 \%)$, chch morphant donor cells were observed in anterior neural structures. In the remaining embryos, the cells were spread over superficial layers of the trunk in 15/ 72 embryos $(20.8 \%)$ or in both neural tissue and superficial cell layers of the trunk in $12 / 72$ embryos $(16.7 \%$, Table 1). Importantly, the movement phenotype produced by the chch-ATGMO could be rescued by co-injection with chch mRNA (Fig. 4J-M). Unlike chch morphant donor cells which were restricted to the superficial layers of the trunk in 15/72 (20.8\%) transplants, cells from chchATGMO + chch mRNA injected donors were never restricted to the superficial layers of the trunk $(0 / 41$ embryos, Fig 4J-M, Table 1). However, in 8/41 (19.5\%) embryos, cells were observed in superficial layers of the trunk and in anterior neural tissue (Table 1), a rate comparable to the control transplant. Cells from chch-EnR mRNA injected donors also underwent similar spreading behavior as the chch morphant cells (data not shown).

These results show that $c h c h$ inhibition results in inappropriate cell movements. To determine if the increase in mesodermal gene expression observed in chch-inhibited embryos (Fig. 2) results from inappropriate cell movements, cell transplant experiments were performed to assay the behavior of chch-EnR and chch-ATGMO cells in wild-type hosts. Since transplantation of sphere stage (mid-blastula) chch compromised donor cells to sphere stage wild-type host resulted in movement of chch compromised donor cells to superficial cell layers, we performed a series of heterochronic transplants to determine if the vegetal migration could result in a mesodermal fate change. Here, sphere (mid-blastula) stage LacZ mRNA, chch-ATGMO or chch-EnR mRNA injected cells were transplanted to the animal hemisphere of 30\% epiboly (lateblastula) stage embryos. Donor cell position was documented at $40 \%$ epiboly ( $5 \mathrm{hpf}$ ), shield stage ( $6 \mathrm{hpf}$ ) and 24 hpf (Fig. 5 and Table 2, 3).

When LacZ cells were transplanted into the animal hemisphere of late-blastula embryos, donor cells remained 


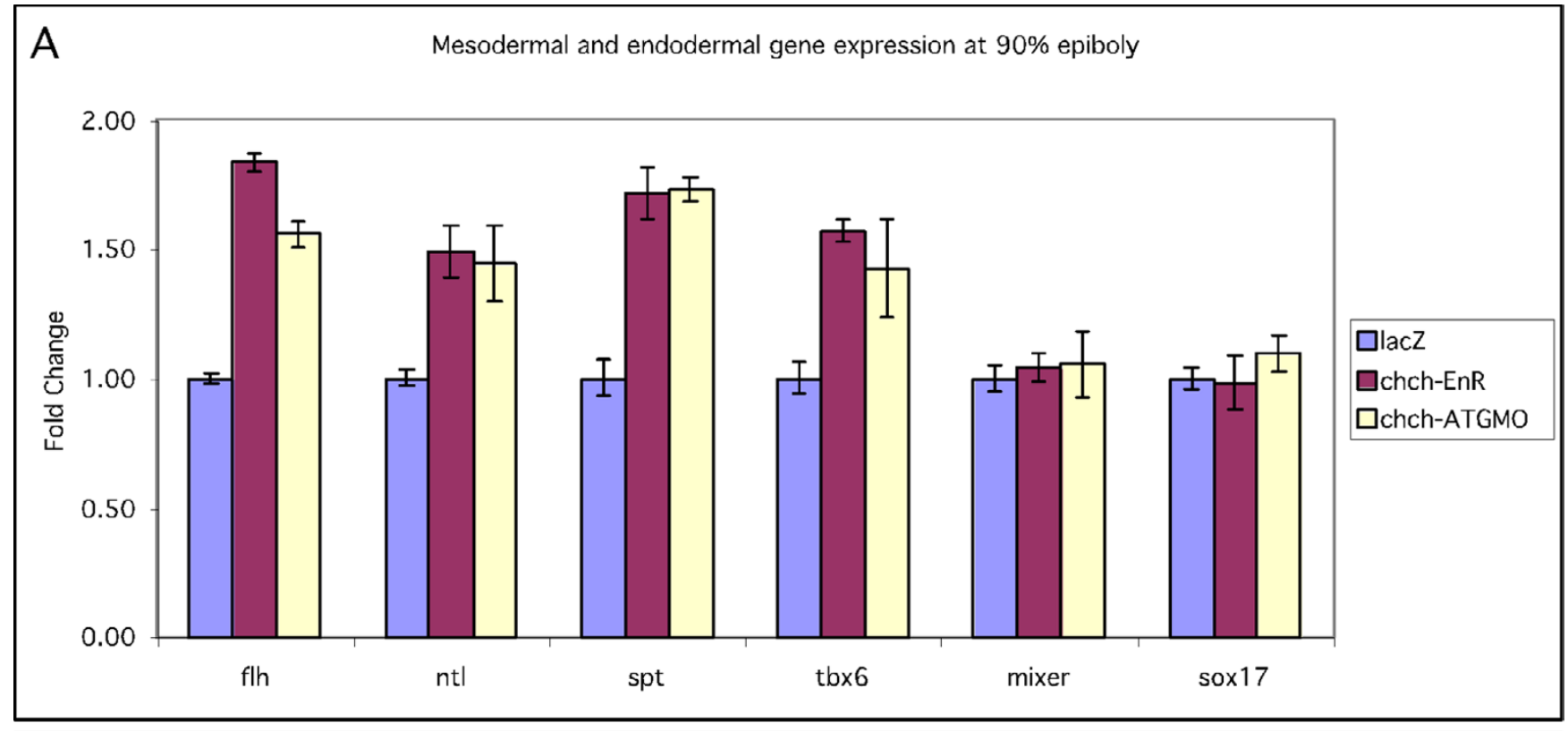

B Ectodermal gene expression at $90 \%$ epiboly
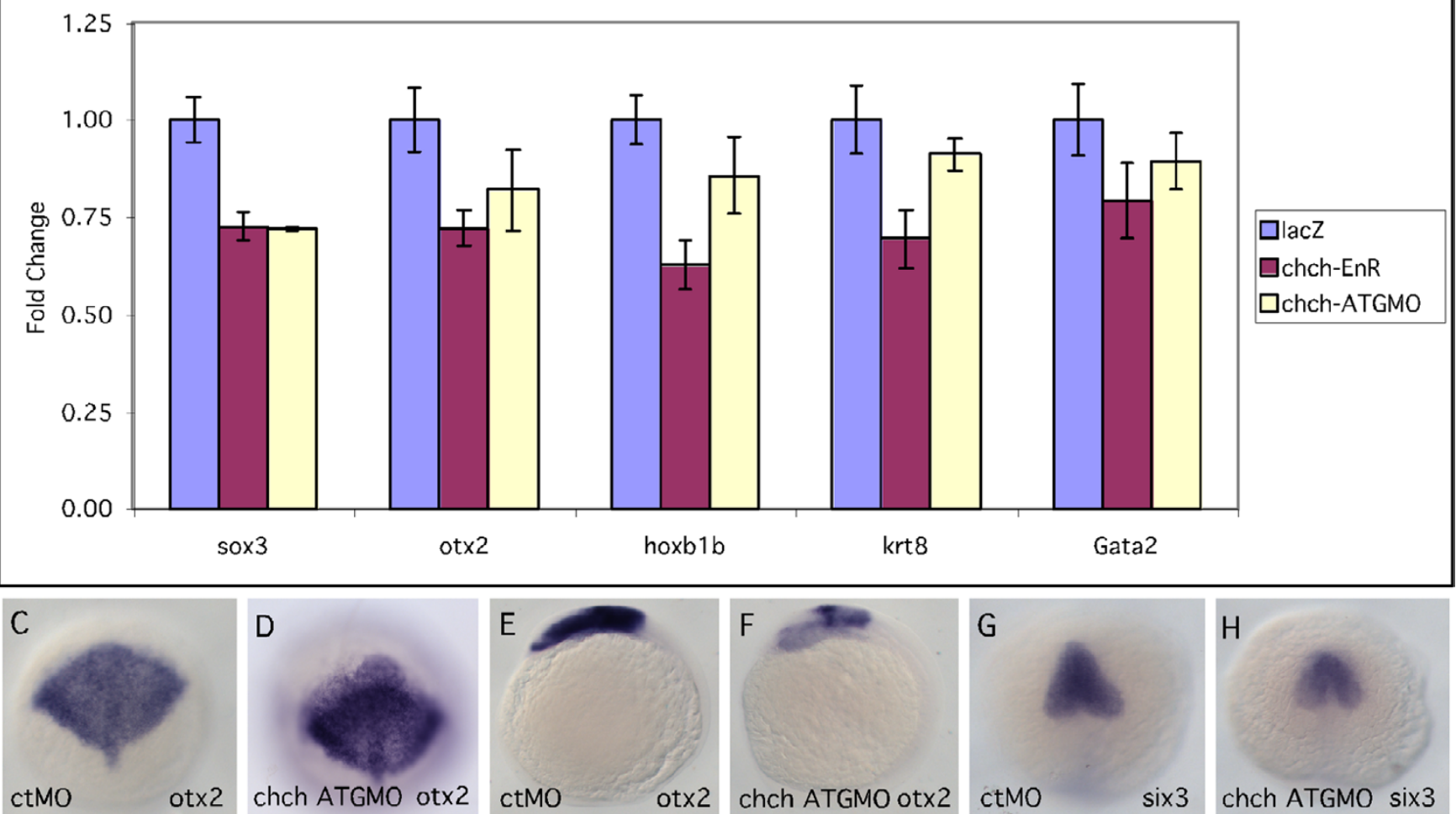

Figure 3

chch inhibition results in decreased ectodermal gene expression. Real-time PCR analysis of mesodermal, ectodermal and endodermal markers during late gastrulation in chch-compromised embryos. The mesodermal markers flh, ntl, spt, and tbx6 (A), endodermal markers, mixer and sox I 7b (A) and ectodermal markers otx2, hoxblb, sox3, krt8 and gata2 (B) were examined following microinjection of chch-EnR mRNA and chch-ATGMO. Mesodermal markers are increased, endodermal are unaffected while ectodermal marker levels are decreased. Expression of the neural genes otx2 at 90\% epiboly (C-D) and 6-somites (E-F) and Six3 at 6-somites (G-H). C-D, G-H are dorsal views. E-F are lateral views. 
A

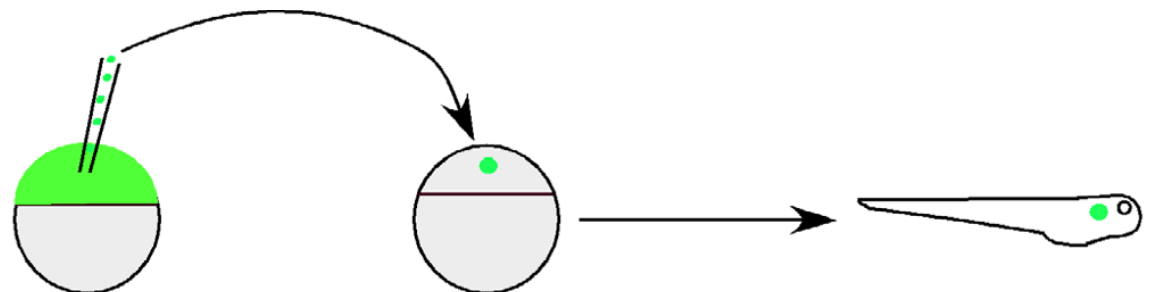

Cells removed from animal pole of sphere stage donor embryos.
$5-15$ cells transplanted to the animal hemisphere of sphere stage WT host embryos.
Embryos grown to $24 \mathrm{hpf}$ and the location of the donor cells are determined

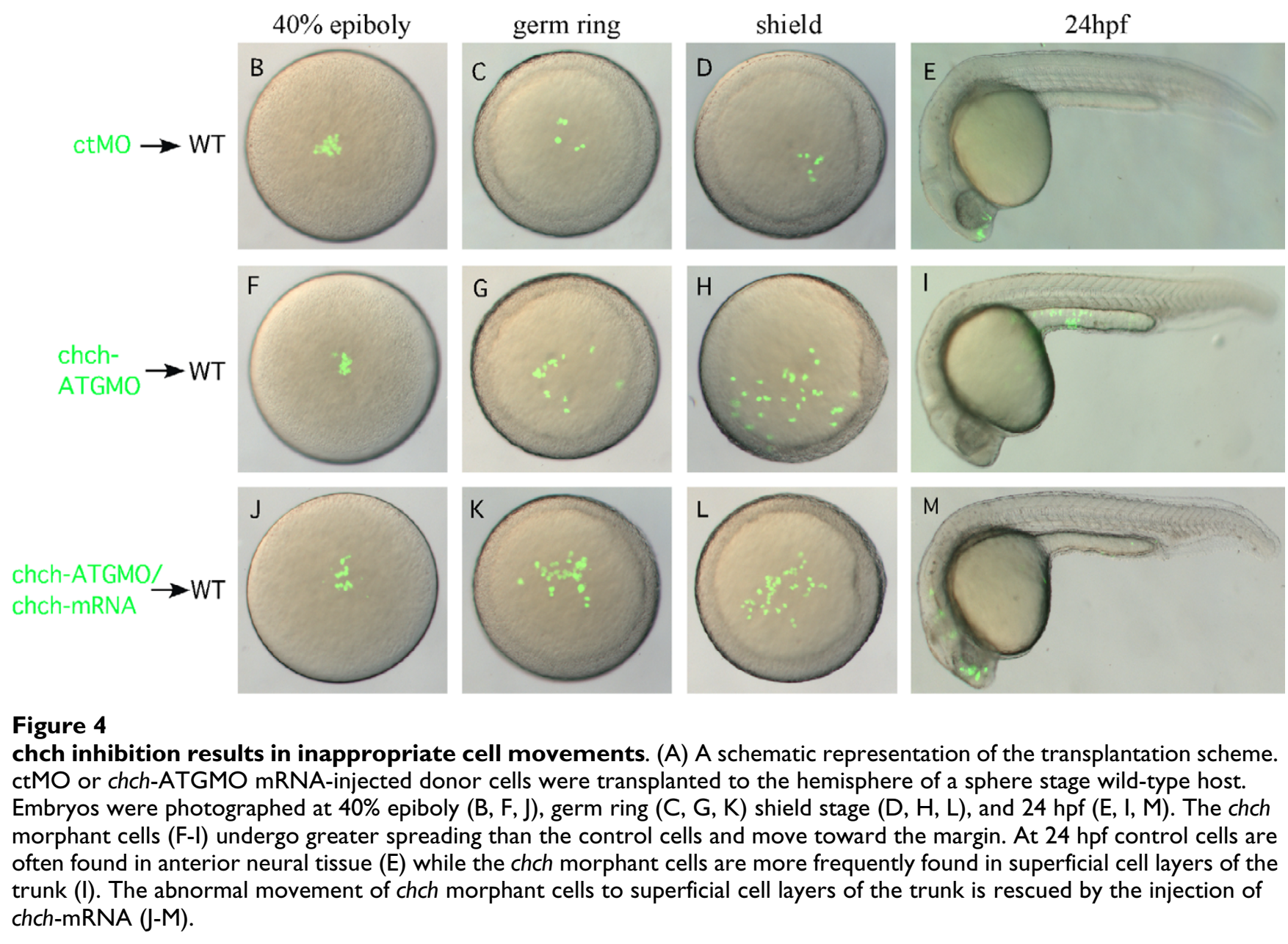

within the ectoderm in 77/79 hosts (Fig. 5B-D, Table 3). Cells with compromised chch function behaved dramatically different in this assay (Fig. 5E-G). In 44/110 $(40.0 \%)$ transplants, chch-EnR donor cells migrated from the epiblast to the germ ring by shield stage (Table 2). The effects of the chch-ATGMO were less pronounced but in $8 / 51$ (15.7\%) transplants, morphant cells migrated from the epiblast to the germ ring (Fig. 5K-M). Cells from donor embryos that had been co-injected with chch-EnR mRNA and chch mRNA tended to remain in the animal hemisphere (Fig. 5H-J, Table 2). In these transplants in only 5/38 (13.2\%) hosts, was migration of donor cells to the germ ring observed. This demonstrates that the migration of chch deficient donor cells can be rescued with chch mRNA and indicates that the defect stems from knockdown of chch function.

To determine whether movement of chch-compromised cells to the germ ring correlated with a fate change in these cells, we determined their locations at $24 \mathrm{hpf}$. Of the chchEnR donor cells that migrated to the germ ring, 38/44 were found in mesodermal structures at $24 \mathrm{hpf}$. Likewise, 
Table I: Transplantation of chch inhibited cells during mid-blastula stages results in inappropriate cell movements.

\begin{tabular}{|c|c|c|c|c|c|}
\hline \multirow[b]{2}{*}{ Treatment } & \multirow[b]{2}{*}{$\mathrm{N}$} & \multicolumn{4}{|c|}{ Location of cells at $24 \mathrm{hpf}$} \\
\hline & & Neural tissue & $\begin{array}{l}\text { Superficial cells spread } \\
\text { over the trunk }\end{array}$ & $\begin{array}{l}\text { Neural and superficial cells } \\
\text { spread over the trunk }\end{array}$ & Mesoderm \\
\hline $\mathrm{CtMO}$ & 52-embryos & 42-embryos & 3-embryo & 7-embryos & 0 -embryos \\
\hline chch-ATG2MO & 72-embryos & 44-embryos & 15-embryos & 12-embryos & I-embryo \\
\hline chch-ATG2MO/chch mRNA & 41 -embryos & 33-embryos & 0 -embryos & 8-embryos & 0 -embryos \\
\hline
\end{tabular}

$8 / 8$ chch morphant donor cells that migrated to the germ ring were later found in mesodermal structures. This demonstrates that chch compromised cells transplanted distant from the margin at 30\% epiboly generated mesoderm while LacZ donor cells did not. In 6/44 transplants, chchEnR donor cells migrated to the germ ring but did not give rise to mesoderm. This suggests that movement of these cells may not entirely be linked to acquisition of mesodermal character.

The location of the chch compromised donor cells after 24 hpf was often not characteristic of their position at shield stage. The chch-EnR cells that migrated out of the ectoderm and into the germ ring also acquired unexpected fates and were found in surprising locations. Cells located in the ventral germ ring would be expected give rise to posterior somites. Instead, these cells were found in more anterior somites (first 15 somites, 10/14 embryos) or were observed in the ectoderm (2/14 embryos) (Table 2). Cells located lateral to the shield would be expected to assume anterior somite fates. While a majority of these cells did give rise to anterior somites (12/20 embryos), cells were also located within the notochord (4/20 embryos) and neural tissue (2/20 embryos) (Table 3$)$. Together, these results suggest that inhibiting chch results in several kinds of inappropriate cell movements including movement of presumptive ectodermal cells into the germ ring.

\section{Migration and fate change of chch compromised cells requires Nodal signaling}

Our initial transplant experiments do not reveal whether the fate changes observed in chch-compromised donor cells result from a failure to limit cell movement or whether a fate change precedes the improper movement. Three models could account for the movement of chchcompromised donor cells to the germ ring and subsequent acquisition of mesodermal character that we observed: 1) chch-compromised donor cells may autonomously express mesodermal markers which drives both movement and acquisition of mesodermal character; 2) inappropriate movement of chch-compromised donor cells to the margin may result in exposure of donor cells to mesoderm inducing signals; or 3) chch-compromised donor cells may exhibit increased sensitivity to non- autonomous signals that drive migration and/or acquisition of mesodermal character. Since induction of trunk mesoderm requires Nodal signaling $[3,18]$, we reasoned that blocking Nodal signaling after transplantation of chch-compromised cells would allow these models to be distinguished. If the first model is correct, migration of chch compromised cells and fate change will occur regardless of the state of Nodal signaling. If inappropriate movement allows chch compromised donor cells to come under the influence of the high levels of Nodal ligands present in the germ ring (model 2), we would observe migration of donor cells, but these cells would be unable to respond to mesoderm inducing signals. If the third model is correct, both migration and acquisition of mesodermal character will be blocked in chch-compromised donor cells when Nodal signaling is abrogated.

To test these hypotheses, cell transplantation experiments were performed with $c h c h$-EnR donor cells placed into the animal hemisphere of wild-type hosts. We used chch-EnR donors instead of chch morphant donors because these cells had a greater tendency to migrate from the epiblast to the germ ring (Table 2). Both donors and hosts were maintained in SB431542 to block Nodal signaling prior to transplantation and returned to SB431542 containing media following transplantation. SB431542 inhibits Alk4, Alk5 and Alk7 kinase activity, and it has been shown to phenocopy Nodal pathway mutants $[19,20]$.

As expected, LacZ expressing cells transplanted from the animal hemisphere of a sphere stage ( $4 \mathrm{hpf}$ ) embryo to the animal hemisphere of a wild-type host at a late blastula stage ( $4.7 \mathrm{hpf}$ ) remained in the animal hemisphere (22/22 embryos) and by $1 \mathrm{dpf}$ were observed in anterior neural tissue (Fig. 6A-A' and Table 4). Treatment with SB431542 did not alter the behavior of these cells (Fig. 6B-B'). Conversely, in the same transplant scheme, chchinhibited cells often migrated to the germ ring and became incorporated into mesodermal structures at $1 \mathrm{dpf}$ (Fig. 6C-C' and Table 4). Surprisingly, when Nodal signaling was blocked, chch-EnR donor cells remained in the animal hemisphere (32/32 embryos) and were observed in anterior neural structures at $1 \mathrm{dpf}(24 / 32$ hosts, Fig. $6 \mathrm{D}-\mathrm{D}$ ' and Table 4$)$. In the remaining $8 / 32$ cases, donor 
A

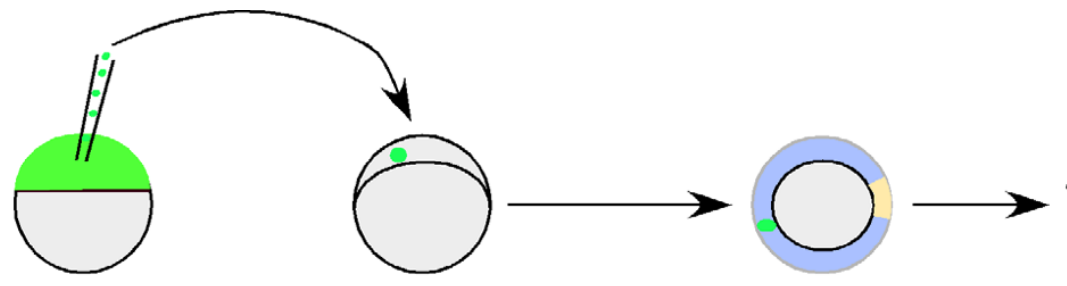

Cells removed from the animal pole of sphere stage donor embryos.
5-15 cells were transplanted At $40 \%$ epiboly and to the animal hemisphere of shield stage, the location a $30 \%$ epiboly stage WT host embryo. of cells was documented and the embryos were sorted.

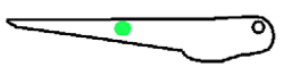

Embryos grown to $24 \mathrm{hpf}$ and the location of the donor cells are determined.

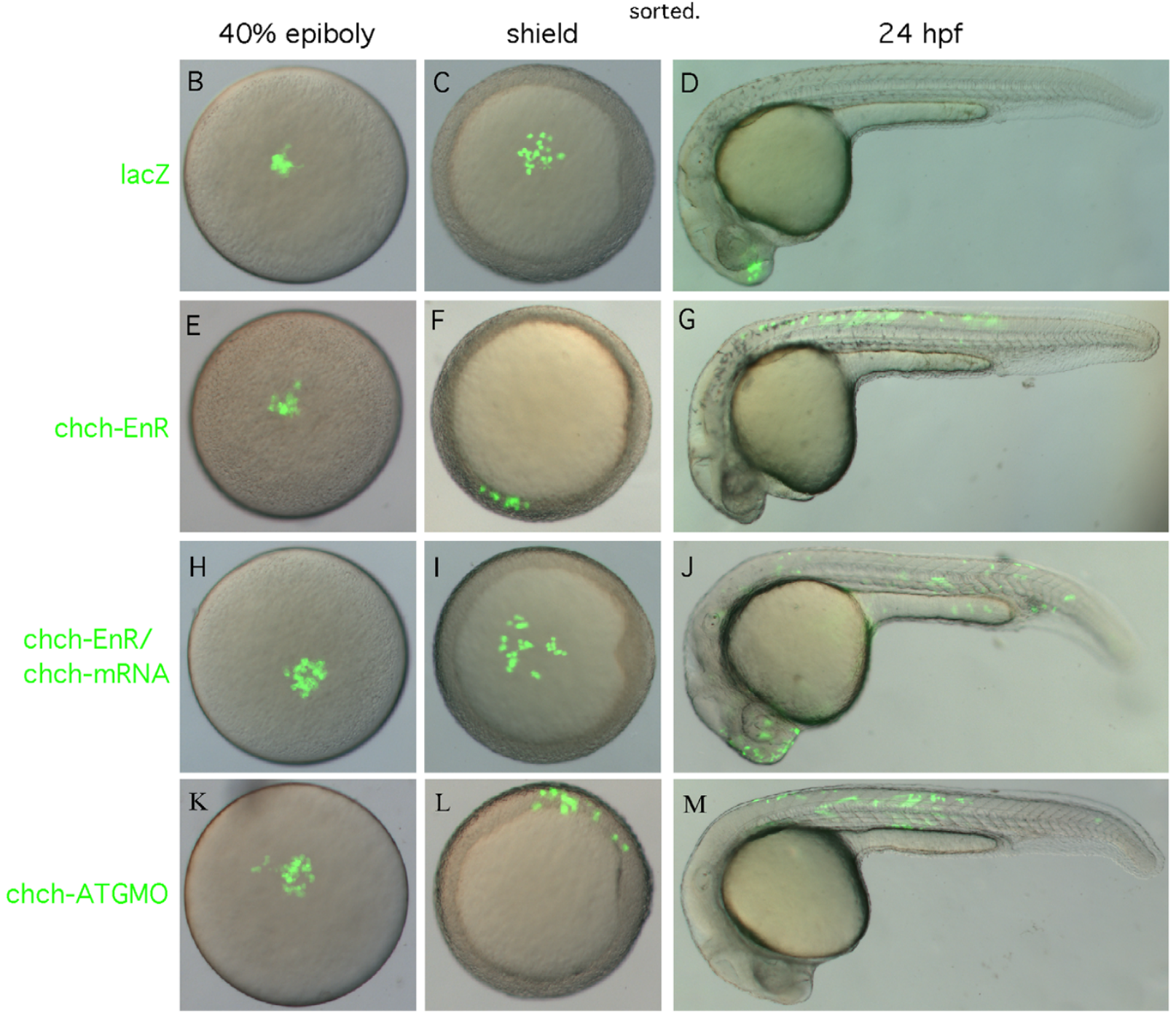

\section{Figure 5}

chch-inhibited cells leave the epiblast and enter the germ ring and become mesoderm. (A) A schematic representation of the transplantation scheme. Cells from sphere stage LacZ, chch-EnR mRNA or chch-ATGMO injected donors were transplanted to the animal hemisphere of $30 \%$ epiboly (late blastula) wild-type embryos. Embryos were photographed at $40 \%$ epiboly (B, E, H, K), at the start of gastrulation (shield) (C, F, I, L) and after $24 \mathrm{hpf}(\mathrm{D}, \mathrm{G}, \mathrm{J}, \mathrm{M})$. As expected, LacZ cells remain within the ectoderm and take on ectodermal fates at $24 \mathrm{hpf}(\mathrm{B}-\mathrm{D})$. In contrast, chch inhibited cells often migrate from the presumptive ectoderm to the germ ring (E-G, K-M). These cells are often later found in the somites (G). The abnormal movement of chch-EnR cells into the germ ring is rescue by coinjection of chch mRNA $(\mathrm{H}-\mathrm{J})$. The images in each row are of the same embryo. 
Table 2: Transplantation of chch-inhibited cells undergo inappropriate movements during gastrulation

\begin{tabular}{ccccccc}
\hline & & \multicolumn{3}{c}{ Location of Cells at shield } \\
\cline { 3 - 7 } Injected mRNA & $\mathbf{N}^{\mathrm{n}}$ & Dorsal Ectoderm & Ventral ectoderm & Shield & Lateral mesoderm & Ventral mesoderm \\
\hline LacZ & 79 & 52 & 25 & 0 & 2 & 0 \\
chch-EnR & 110 & 38 & 28 & 10 & 20 & 2 \\
chch-EnR/chch-mRNA & 38 & 20 & 13 & 0 & 5 & 2 \\
chch-ATGMO & 51 & 26 & 17 & 1 & 5 \\
\hline
\end{tabular}

a-Host embryos with cells in the presumptive ectoderm at $40 \%$ epiboly

cells were scattered in superficial layers of the yolk (likely epidermis). The behavior of this subset of cells differs from LacZ donors and non-SB431542 treated chch-EnR donors and may stem from an incomplete block of Nodal signaling. These findings demonstrate that signaling via Alk receptors is required for both migration to the germ ring and acquisition of mesodermal character of the chchEnR donor cells. Since SB431542 treatment blocked Alk signaling in both donor and host cells, we could not infer which cells required Alk-mediated signaling from these experiments.

To establish whether Nodal signaling is required in the donor or host cells we employed two manipulations to repress Nodal signaling in the donor cells. These experiments utilized MZoep mutants which lack Oep, an EGFCFC protein that functions as a co-receptor for Nodal signals [3] or dominant-negative xFAST1-EnR mRNA. MZoep embryos are completely non-responsive to Nodal signals. Fast 1 (or FoxH1) is a transcription factor that responds to Nodal and FAST1-EnR constructs are effective in blocking Nodal signaling in fish and frogs $[21,22]$.
Donor cells were removed at $4 \mathrm{hpf}$ either from the animal pole of an MZoep embryo injected with chch-EnR mRNA or from a wild-type donor injected with $c h c h$-EnR and xFast1-EnR mRNA. First, control or chch-inhibited MZoep cells were transplanted to the animal hemisphere of a wild-type host embryo at a late blastula stage (4.7 hpf). LacZ injected MZoep cells behaved similarly to wild-type cells. These donor cells did not leave the animal hemisphere and were observed in anterior neural structures at $1 \mathrm{dpf}$ (Fig. 7A-A'). Similar to the SB431542 experiment, chch-EnR-MZoep cells remained in the animal hemisphere (48/48 embryos), and were observed in anterior neural tissues at 24 hpf (Fig. 7B-B' and Table 4) demonstrating that Oep is required for both migration and fate change of the chch-EnR donor cells.

We next transplanted cells from donor embryos coinjected with $c h c h$-EnR and xFast1-EnR to wild-type hosts. Following transplantation of LacZ cells, little movement of donor cells was observed at $6 \mathrm{hpf}$ and donor cells were found in anterior neural structures at $1 \mathrm{dpf}$ (Fig. 7C-C' and Table 4). Similarly, transplanted chch-EnR/xFast1-

Table 3: Transplantation of chch-inhibited cells undergo inappropriate movements during gastrulation and results in cells in the mesoderm.

\begin{tabular}{|c|c|c|c|c|c|c|c|}
\hline \multirow[b]{2}{*}{ Location of cells at shield stage } & \multirow[b]{2}{*}{ Injected mRNA } & \multirow[b]{2}{*}{$\mathbf{N}^{b}$} & \multicolumn{5}{|c|}{ Location of cells at $24 \mathrm{hpf}$} \\
\hline & & & $\begin{array}{c}\text { Neural } \\
\text { tissue }\end{array}$ & Epidermis & Notochord & $\begin{array}{l}\text { Anterior } \\
\text { somites }\end{array}$ & $\begin{array}{c}\text { Posterior } \\
\text { somites }\end{array}$ \\
\hline \multirow[t]{4}{*}{ Shield } & LacZ & 0 & 0 & 0 & 0 & 0 & 0 \\
\hline & chch-EnR & 10 & 2 & 0 & 6 & 2 & 0 \\
\hline & chch-EnR/chch-mRNA & 0 & 0 & 0 & 0 & 0 & 0 \\
\hline & chch-ATGMO & I & 0 & 0 & I & 0 & 0 \\
\hline \multirow[t]{4}{*}{ Lateral Mesoderm } & LacZ & 1 & 0 & 0 & 0 & 1 & 0 \\
\hline & chch-EnR & 20 & 2 & 0 & 4 & 12 & 2 \\
\hline & chch-EnR/chch-mRNA & 2 & 0 & 0 & 0 & 2 & 0 \\
\hline & chch-ATGMO & 5 & 0 & 0 & 0 & 2 & 3 \\
\hline \multirow[t]{4}{*}{ Ventral Mesoderm } & LacZ & 0 & 0 & 0 & 0 & 0 & 0 \\
\hline & chch-EnR & 14 & I & I & 0 & 10 & 2 \\
\hline & chch-EnR/chch-mRNA & 3 & 0 & 0 & 0 & 2 & I \\
\hline & chch-ATGMO & 2 & 0 & 0 & 0 & 1 & 1 \\
\hline
\end{tabular}

\footnotetext{
b-Same embryos were scored at $40 \%$ epiboly, shield stage and 24 hrs
} 
Table 4: Transplantation of chch-EnR cells requires nodal signaling for cell movements and fate changes

\begin{tabular}{|c|c|c|c|c|c|c|c|c|c|}
\hline \multirow[b]{2}{*}{ Donor cells } & \multirow[b]{2}{*}{ Host embryos } & \multirow[b]{2}{*}{$\mathbf{n}$} & \multicolumn{2}{|c|}{$\begin{array}{l}\text { Location of cells } \\
\text { at shield }\end{array}$} & \multicolumn{5}{|c|}{ Location of Cells at $24 \mathrm{hpf}$} \\
\hline & & & $\begin{array}{l}\text { Animal } \\
\text { pole }\end{array}$ & $\begin{array}{l}\text { Germ } \\
\text { ring }\end{array}$ & Neural & Epidermis & Somites & Notochord & $\begin{array}{c}\text { Yolk } \\
\text { (Superficial) }\end{array}$ \\
\hline LacZ & Wild-type & 22 & 22 & 0 & 19 & 3 & 0 & 0 & 0 \\
\hline LacZ & Wild-type + SB43I542 & 25 & 25 & 0 & 25 & 0 & 0 & 0 & 0 \\
\hline chch-EnR & Wild-type & 32 & 19 & 13 & 11 & 1 & 17 & 2 & 0 \\
\hline chch-EnR & Wild-type + SB43I542 & 32 & 32 & 0 & 24 & 0 & 0 & 0 & 8 \\
\hline MZoep-LacZ & Wild-type & 36 & 35 & I & 29 & 7 & 0 & 0 & 0 \\
\hline Mzoep-chch-EnR & Wild-type & 48 & 48 & 0 & 41 & 6 & 1 & 0 & 0 \\
\hline LacZ & Wild-type & 26 & 26 & 0 & 23 & 3 & 0 & 0 & 0 \\
\hline chch-EnR/xFsastI-EnR & Wild-type & 38 & 38 & 0 & 26 & 6 & 0 & 0 & 6 \\
\hline
\end{tabular}

EnR co-injected donor cells (Fig. 7D-D' and Table 4) remained in the animal hemisphere and gave rise to anterior neural tissue (26/38 embryos), epidermis (6/32 embryos) or were on the superficial surface of the yolk (6/ 32 embryos). This result suggests that xFast1-EnR prevents chch-EnR cells from adopting mesodermal fates. However, some chch-EnR/xFast1-EnR co-injected donor cells behave differently than the LacZ donors and are found spread across the yolk at $1 \mathrm{dpf}$. These donor cells likely retain some responses to Nodal since some Nodal signaling events are independent of xFast 1 and are instead mediated by Mixer-related molecules [23].
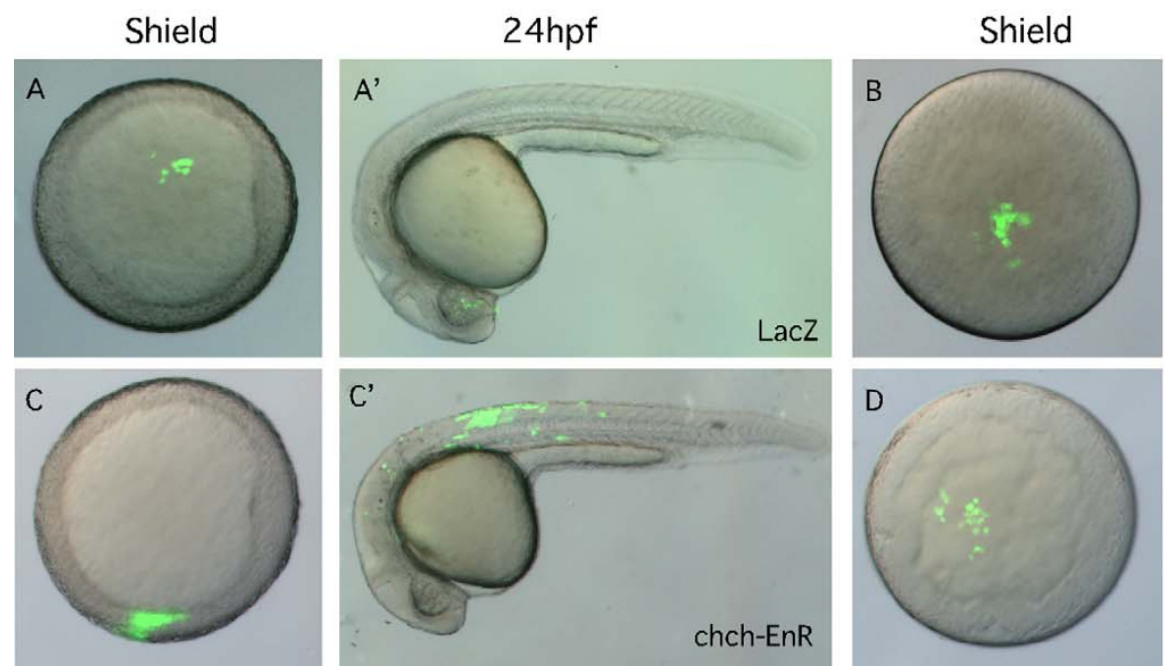

Since chch-compromised cells fail to migrate to the germ ring and to assume mesodermal fates if Alk, Oep or Fast1 function is abrogated, we conclude that both migration and fate change depends on Nodal signaling. In the xFast1-EnR and SB431542 experiments, some chch-EnR cells underwent aberrant movements but were not later observed in mesodermal structures suggesting that migration and fate change can be uncoupled.

\section{chch-EnR embryos have enhanced response to Nodal}

The above results suggest that the chch-EnR cells placed in the animal hemisphere respond to a Nodal signal but

\section{Figure 6}

Alk receptor signaling is required for both migration and acquisition of mesodermal character of chch-EnR transplanted cells. Transplanted LacZ cells were present in the animal pole at shield stage (A) and were found in anterior neural tissue after 24 hpf (A'). $400 \mu$ M SB43 542 (Sigma-Aldrich), which inhibits Alk receptors did not alter LacZ donor cell behavior (B-B'). Conversely, chch-EnR donor cells moved from the animal hemisphere to the germ ring by shield stage $(C)$ and were observed in mesodermal structures after $24 \mathrm{hpf}\left(\mathrm{C}^{\prime}\right)$. SB43 1542 treatment results in blocking movement of chch-EnR cells. The donor cells remain in the animal hemisphere at shield stage (D) and are found in anterior neural structures after $24 \mathrm{hpf}\left(\mathrm{D}^{\prime}\right)$. This result suggests that signaling via Alk receptors is required for both migration and acquisition of mesodermal character of chch-EnR donor cells. The images in each row are of the same embryo. 
Shield
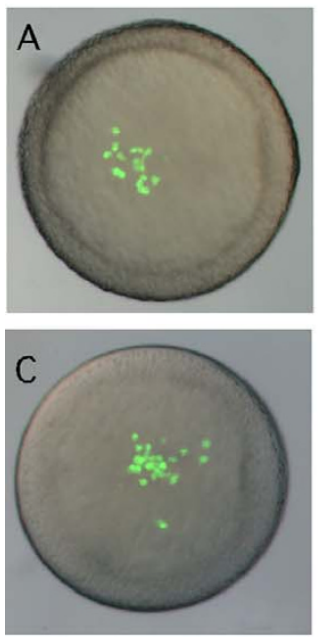

24hpf
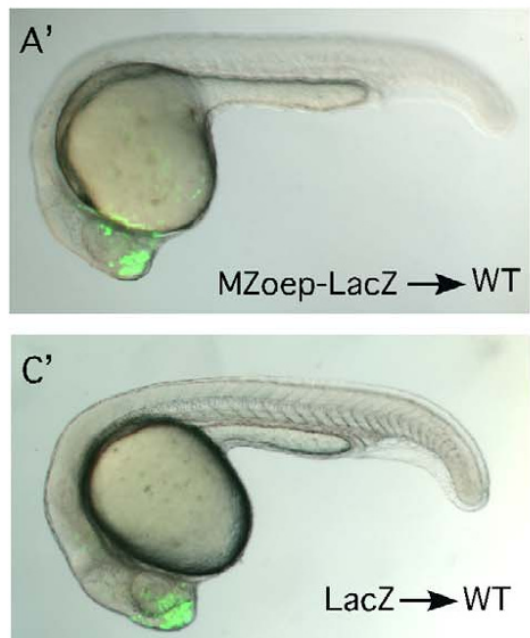

Shield
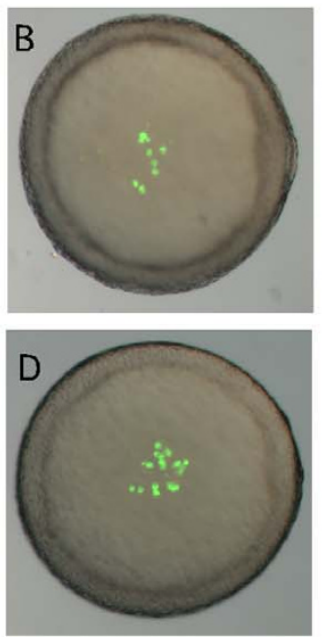

24hpf
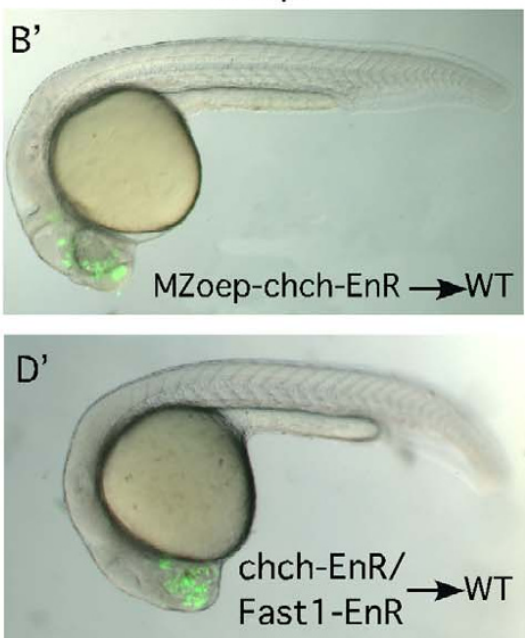

Figure 7

chch-compromised cells migrate to the germ ring and become mesoderm in response to Nodal signals. Transplanted MZoep-LacZ cells to the animal hemisphere of a wild-type host remain within the animal hemisphere at shield stage (A) and are observed in anterior neural structures after $24 \mathrm{hpf}\left(\mathrm{A}^{\prime}\right)$. Similar behavior was observed for transplanted MZoep-chchEnR cells in wild-type hosts (B-B'). Similarly, when donor cells express 12.5 pg xFast I-EnR, along with chch-EnR, migration to the margin is blocked and donor cells are observed in anterior neural structures after 24 hpf (D-D'). Together, these results demonstrate that the migration of the chch inhibited cells to the germ ring and acquisition of mesodermal character depends upon Nodal signaling.

wild-type cells do not. Since Nodal ligands are expressed at the margin during late blastula and early gastrula stages, we tested the hypothesis that chch-compromised cells have increased responsiveness to low levels of Nodal. Wild-type embryos were microinjected with chch-EnR mRNA, 0.5 pg or 2.5 pg of sqt mRNA, chch-EnR mRNA and $s q t$ mRNA or LacZ mRNA. Embryos were collected at shield stage and the levels of five genes whose expression depends on Nodal signaling were measured by real-time PCR. These genes included the dorsal markers, chd, gsc, flh, as well as the pan-mesodermal marker $n t l$ and the endodermal marker mixer (Fig. 8). All of these markers show no change or modest changes in embryos injected with chchEnR mRNA and a dose-dependent response to $s q t$ mRNA (Fig. 8A-E). Synergistic increases were observed when both chch-EnR mRNA and sqt mRNA were co-injected. For example, microinjection of $2.5 \mathrm{pg}$ of $s q t$ mRNA resulted in a 3.5 fold increase in chd mRNA levels (Fig. 8A). When chch-EnR mRNA was coinjected with $2.5 \mathrm{pg}$ of $s q t$, a greater than 7 -fold increase in chd mRNA levels were measured.

Overexpression of chch mRNA had little effect in suppressing the effects of $s q t$ overexpression on the same markers when assayed by real-time PCR at shield stage (Fig. 8F-J). However, we found that overexpression of zebrafish chch fused to the VP16 transcriptional activator domain (chchVP16) was able to suppress the effects of Nodal activation
(Fig. 8F-J). The endogenous levels of $c h d$, gsc and $n t l$ were also suppressed by microinjection of chch-VP16 mRNA. Levels of mixer and flh were unaltered by microinjection of either chch mRNA or chch-VP16 mRNA. Together results demonstrate that chch functions to suppress the response to Nodal signaling.

\section{Discussion}

We characterized the function of the zinc finger transcription factor Churchill in zebrafish. Our data showed that chch is required to repress expression of markers of nonaxial mesoderm, while both neural and presumptive epidermal markers are diminished in chch-compromised embryos. In transplant assays, cells with compromised chch function undergo atypical cell movements when placed in the animal hemisphere and acquire fates inappropriate for their position in the early gastrula. Unlike control cells, these donor cells often migrate to the margin and are later observed in mesodermal derivatives. The movement and corresponding fate change of the transplanted chch compromised cells can be suppressed by blocking Nodal signaling in the donor cells. Finally, we demonstrate that chch suppresses the transcriptional response to Nodal signaling.

\section{chch limits expression of mesodermal markers}

In Xenopus, chch overexpression is sufficient to repress Xbra expression [15]. Our data demonstrate that when 

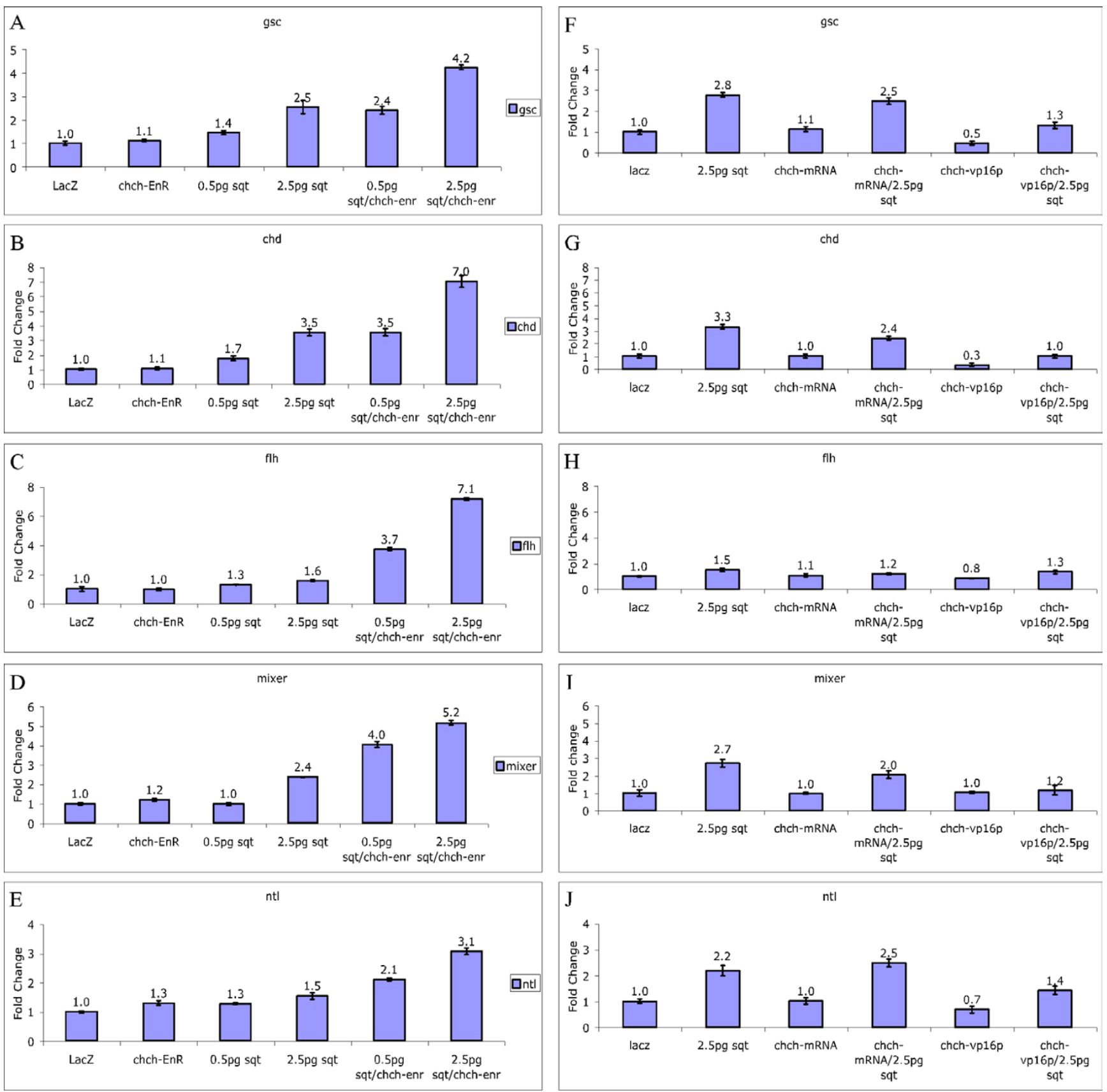

Figure 8

chch suppresses the transcriptional response to Nodal signaling. Embryos were microinjected with either 250 pg chchEnR mRNA, 0.5 pg sqt mRNA, 2.5 pg sqt mRNA, or co-injected with 250 pg chch-EnR mRNA and 0.5 pg or 2.5 pg sqt mRNA and were analyzed at shield stage by real-time PCR with the dorsal markers gsc (A), chd (B), and flh (C), the endodermal marker mixer (D) and the pan-mesodermal marker $n t(\mathrm{E})$. All of these markers show little change in gene expression in embryos injected with chch-EnR mRNA and a dose dependent response to sqt mRNA. When both chch-EnR and sqt mRNA were co-injected, synergistic increases in marker expression were observed. These results demonstrate that chch suppresses the response to Nodal signaling. Conversely, microinjection of chch-VP-I6 mRNA suppresses the transcriptional response to Nodal signaling. Embryos were microinjected with 2.5 pg sqt, 500 pg chch mRNA, 500 pg chch-VPI 6 mRNA, or co-injected with sqt and chch mRNA or chch-VPI6 mRNA. Embryos were collected at shield stage and analyzed by real-time PCR with gsc (F), chd $(\mathrm{G})$, fh $(\mathrm{H})$, mixer (I), and $n t l(\mathrm{~J})$. Co-injection of chch-VPI 6 mRNA along with sqt mRNA supresses the transcriptional response to sqt. 
chch function is repressed, mesodermal gene expression is expanded during gastrulation (Fig. 2) and the expansion corresponds to a decrease in the levels of ectodermal markers (Fig. 3). The effects on ectoderm are relatively modest during gastrulation but at later stages anterior neural defects were observed.

In contrast to Xenopus, we did not detect repression of $n t l$ (brachyury) when chch is overexpressed (Fig. 2I-J). Since the concentration of chch mRNA used in the overexpression experiments was sufficient to rescue both the morpholino and dominant-negative phenotypes, these levels are likely physiologically relevant. Overexpression of higher doses of $c h c h$ mRNA failed to alter early $n t l$ expression (data not shown). However, we do observe repression of $n t l$ following microinjection of $c h c h$-VP16 mRNA (Fig. 8). The different effects of chch overexpression on brachyury expression may reflect experimental differences or divergence in regulation of brachyury between fish and frogs. One possibility is that an essential chch or Sip1 cofactor is widely expressed in Xenopus but has restricted expression in zebrafish.

\section{chch regulates cell movement}

We show that cells with compromised chch function undergo inappropriate cell movements. When placed into a wild-type embryo at a late blastula stage, these cells often leave the epiblast, migrate to the germ ring and become mesoderm (Fig. 5). This result is consistent with the chch study in the chick, where chch was shown to be required to repress ingression of epiblast cells into the primitive streak [15]. These data suggest an evolutionarily conserved function for $\mathrm{chch}$ in the regulation of cell movement during gastrulation.

A key question is whether the chch compromised cells that leave the epiblast and enter the germ ring, become mesoderm because chch regulates migration and they are subsequently exposed to mesoderm-inducing signals in the germ ring or whether they migrate to the germ ring because they have already established mesodermal identity; is movement directing fate or is fate controlling movement?

The transplant experiments in which we manipulated the responsiveness of the donor cells to Nodal signaling revealed that chch-EnR cells do not autonomously become mesoderm but require activation of the Nodal pathway to migrate to the germ ring and adopt mesodermal fates. When Nodal signaling is blocked, chch-compromised cells fail to migrate to the germ ring and do not assume mesodermal fates (Fig 6, 7). Analysis of zebrafish Nodal mutants has shown that Nodal signaling is required for internalization of mesodermal precursors [24]. Our results suggest that Nodal may also play a role in cell movement toward the margin prior to internalization. The Nodal family member responsible for this activity has not been established, although Sqt is a strong candidate because it is expressed at these stages and has been shown to act as a long-range signal [25]. Alternatively, the movement of chch-compromised donor cells may be influenced by another Nodal family member, perhaps $\mathrm{Vg} 1$ which is also expressed early and requires Oep function $[26,27]$.

It is important to note that not all cells that underwent unusual movements ended up in the mesoderm. This implies that movement can be uncoupled from acquisition of mesodermal character. Since not all of the donor cells showed the same movements, the differences may have resulted in variations in the initial positions of cells or subtle differences in chch activity in the donor cells. In addition to an enhanced responsiveness to Nodal signals, chch-compromised cells might also be sensitive to other TGF- $\beta$ signals including BMPs, which could account for alterations in cell behavior. More detailed analysis of the behavior of chch-deficient cells will be necessary to determine additional roles for chch in regulating cell movements during gastrulation.

\section{chch represses the transcriptional response to Nodal}

We found that the transcriptional response to the Nodal ligand $s q t$ is enhanced in embryos expressing chch-EnR mRNA. The mRNA levels of five Nodal target genes were synergistically increased when $s q t$ and $c h c h$-EnR mRNA where co-injected (Figure 8). Three of these targets, chd, fh and $g s c$ are expressed in the dorsal mesoderm. The fourth, mixer, is an endodermal marker. However, in contrast to pan-mesodermal markers like $n t l$ (Fig. 2 and 8) and spt (Fig. 2), the transcript levels of these markers were largely unaltered by chch-EnR mRNA or chch-ATGMO microinjection. This suggests that endogenous chch does not play a role in suppressing the high levels of Nodal signaling that are required for specification of dorsal mesoderm and endoderm but represses the response to lower Nodal levels.

Our data suggests that the increased expression of mesodermal markers observed when chch is repressed results from an enhanced response to Nodal. Microinjection of morpholinos directed against the extracellular Nodal antagonist, Lefty, also result in expansion of mesodermal markers $[5,28,29]$. The chch target Sip 1 likely mediates the effect of chch on Nodal signaling. Sip1 has not been previously characterized in zebrafish, although we established that zebrafish Sip1 is regulated by chch (Fig. $2 \mathrm{~K}-\mathrm{N}, \mathrm{Q}$ ). Sip1 represses TGF- $\beta$ signaling by binding to activated forms of Smad1/5 and Smad2/3 [30,31] and is a direct repressor of Xbra [32]. The decrease in Sip1 expression following chch inhibition could result in a failure to check Nodal signaling, which results in mesoderm expansion. 
However, Sip1 morpholinos do not alter Xbra expression in Xenopus [33]. The increase in mesodermal gene expression we observe in chch-compromised embryos (Fig. 2) is consistent with an enhanced sensitivity to TGF- $\beta$ signals. In addition to suppressing Xbra and TGF- $\beta$ signaling, Sip1 is also a direct repressor of E-Cadherin [34]. While migration of chch-compromised cells to the germ ring depends on Nodal signaling, alterations in E-cadherin levels may also influence the unusual movements of these cells.

\section{Conclusion}

Our study of the zinc finger transcription regulator, chch, is the first analysis of the function of this gene in zebrafish. We have discovered roles for $c h c h$ in regulating cell movements within the gastrula that are consistent with the initial data on chch in the chick and Xenopus. Significantly, we have identified several novel functions for chch. Our data suggests a broader role for $c h c h$ then was previously demonstrated and provides key insight into the mechanism of action of chch. From this analysis we conclude: (1) that chch is required to limit mesodermal gene expression; (2) chch inhibits Nodal-dependant movement of presumptive ectodermal cells (3) chch represses the transcriptional response to Nodal signaling. These findings provide a basis to begin to elucidate the dynamic roles for chch in regulating cell movement and fate during early development.

\section{Methods}

\section{Constructs and morpholinos}

The Churchill coding sequence was cloned into the StuI site of the pCS2 plasmid, pCS2-EnR (chch-EnR) or pCS2VP16 (chch-VP16). Sense mRNA was made using the mMESSAGE mMACHINE RNA synthesis kit (Ambion). Morpholinos were synthesized by GeneTools (Philomath, OR): chch-ATGMO-5'-GCTTCTGGACACAACCGGTACACAT

\section{RNA in situ hybridization and photography}

RNA in situ hybridization, probes and photography techniques were previously described [7].

\section{Real-time PCR}

PCR and primers were previously described [7], except chch: F-5'-TGTGTCCAGAAGCAATATCC, R-5'-TCCTCCTCATCTTCATTCAC; Sip1: F-5'-CACTCAGCTGGAGAGACATA, R-5'-TGCTCCTTTAGATGGTGTTT; Mixer F-5'CAGAATCGAGAATTCAGGTC, R-5'-TGTGGTAAACTGGTGCATAA.

\section{Cell transplants}

Embryos were microinjected with either LacZ mRNA for a control chch-ATGMO, or chch-EnR mRNA for the experimentals along with $5 \mathrm{mg} / \mathrm{ml}$ Fluorescein dextran (Molecular Probes). For the isochronic transplants, cells from sphere stage embryos were transplanted to a sphere stage host embryo. For the heterochronic transplants, sphere stage cells were transplanted to the animal hemisphere of $30 \%$ epiboly embryos. Each transplant consisted of 5-15 cells. The location of the transplanted cells was scored and documented immediately after the transplantation and again at shield stage (early gastrulation). Embryos were sorted based upon the location of the transplanted cells relative to the shield (in the shield, lateral or ventral to the shield, or in the ectoderm), and photographed. The location of the cells was observed again after $24 \mathrm{hrs}$ and documented.

\section{Authors' contributions}

EL carried out the transplant and real-time PCR experiments, LM carried out the whole mount RNA in situ hybridizations and imaging. HS conceived of the study, and participated in its design and coordination. All authors read and approved the final manuscript.

\section{Acknowledgements}

We thank Scott Dougan, Ben Feldman, Nathalia Glickman-Holtzman, Will Talbot, Fatma Kok and Keith Gates for helpful suggestions and comments; Richard Grady, Mihoko Yamamoto and Susanna Li for Fish care. We are also grateful to the many labs that provided reagents. This work was supported by NIH grant IROIHD043998 (HS).

\section{References}

I. Warga RM, Kimmel CB: Cell movements during epiboly and gastrulation in zebrafish. Development 1990, I 08(4):569-580.

2. Feldman B, Dougan ST, Schier AF, Talbot WS: Nodal-related signals establish mesendodermal fate and trunk neural identity in zebrafish. Curr Biol 2000, I0(9):531-534.

3. Gritsman K, Zhang J, Cheng S, Heckscher E, Talbot WS, Schier AF: The EGF-CFC protein one-eyed pinhead is essential for nodal signaling. Cell I999, 97(I): I2I-I32.

4. Thisse B, Wright CV, Thisse C: Activin- and Nodal-related factors control antero-posterior patterning of the zebrafish embryo. Nature 2000, 403(6768):425-428.

5. Feldman B, Concha ML, Saude L, Parsons MJ, Adams RJ, Wilson SW, Stemple DL: Lefty antagonism of Squint is essential for normal gastrulation. Curr Biol 2002, I 2(24):2 I 29-2I 35.

6. Furthauer M, Van Celst J, Thisse C, Thisse B: Fgf signalling controls the dorsoventral patterning of the zebrafish embryo. Development 2004, I 3 I ( I 2):2853-2864.

7. Londin ER, Niemiec J, Sirotkin HI: Chordin, FGF signaling, and mesodermal factors cooperate in zebrafish neural induction. Dev Biol 2005, 279(I): I-I9.

8. Alvarez IS, Araujo M, Nieto MA: Neural induction in whole chick embryo cultures by FGF. Dev Biol 1998, I 99(I):42-54.

9. Storey KG, Goriely A, Sargent CM, Brown JM, Burns HD, Abud HM, Heath JK: Early posterior neural tissue is induced by FGF in the chick embryo. Development 1998, I 25(3):473-484.

10. Sun X, Meyers EN, Lewandoski M, Martin GR: Targeted disruption of Fgf8 causes failure of cell migration in the gastrulating mouse embryo. Genes Dev 1999, I3( I4): I834- I846.

II. Yamaguchi TP, Harpal K, Henkemeyer M, Rossant J: fgfr-l is required for embryonic growth and mesodermal patterning during mouse gastrulation. Genes Dev 1994, 8(24):3032-3044.

12. Amaya E Musci, T. J., and Kirschner, M. W.: Expression of a dominant-negative mutant of the FGF receptor disrupts mesoderm formation in Xenopus embryos. Cell 1991, 66:257-270.

13. Griffin K, Patient R, Holder N: Analysis of FGF function in normal and no tail zebrafish embryos reveals separate mechanisms for formation of the trunk and the tail. Development | 995, I 2 I (9):2983-2994. 
14. Hongo I, Kengaku M, Okamoto H: FGF signaling and the anterior neural induction in Xenopus. Dev Biol 1999, 216(2):56I-58I.

15. Sheng G, dos Reis M, Stern CD: Churchill, a zinc finger transcriptional activator, regulates the transition between gastrulation and neurulation. Cell 2003, II5(5):603-6I3.

16. Londin ER, Mentzer L, Gates KP, Sirotkin HI: Expression and regulation of the zinc finger transcription factor Churchill during zebrafish development. Gene Expr Patterns 2007, 7(6):645-650

17. Lerchner W, Latinkic BV, Remacle JE, Huylebroeck D, Smith JC: Region-specific activation of the Xenopus brachyury promoter involves active repression in ectoderm and endoderm: a study using transgenic frog embryos. Development 2000, I 27( I 2):2729-2739.

18. Feldman B, Gates MA, Egan ES, Dougan ST, Rennebeck G, Sirotkin HI, Schier AF, Talbot WS: Zebrafish organizer development and germ-layer formation require nodal- related signals. Nature 1998, 395(6698): $181-185$.

19. Sun Z, Jin P, Tian T, Gu Y, Chen YG, Meng A: Activation and roles of ALK4/ALK7-mediated maternal TGFbeta signals in zebrafish embryo. Biochem Biophys Res Commun 2006 345(2):694-703.

20. Ho DM, Chan J, Bayliss P, Whitman M: Inhibitor-resistant type receptors reveal specific requirements for TGF-beta signaling in vivo. Dev Biol 2006, 295(2):730-742.

21. Pogoda HM, Solnica-Krezel L, Driever W, Meyer D: The zebrafish forkhead transcription factor FoxHI/Fast I is a modulator of nodal signaling required for organizer formation. Curr Biol 2000, I O(I7): 104I-1049.

22. Watanabe M, Whitman M: FAST-I is a key maternal effector of mesoderm inducers in the early Xenopus embryo. Development I999, I 26(24):562 I-5634.

23. Kunwar PS, Zimmerman S, Bennett JT, Chen Y, Whitman M, Schier AF: Mixer/Bon and FoxHI/Sur have overlapping and divergent roles in Nodal signaling and mesendoderm induction. Development 2003, I30(23):5589-5599.

24. Carmany-Rampey A, Schier AF: Single-cell internalization during zebrafish gastrulation. Curr Biol 200I, I I(16): | $26 \mid-1265$.

25. Chen Y, Schier AF: The zebrafish Nodal signal Squint functions as a morphogen. Nature 200 I, $4 \mathrm{II}$ I(6837):607-6I0.

26. Cheng SK, Olale F, Bennett JT, Brivanlou AH, Schier AF: EGF-CFC proteins are essential coreceptors for the TGF-beta signals VgI and GDFI. Genes Dev 2003, I7(I):3I-36.

27. Helde KA, Grunwald DJ: The DVR-I (VgI) transcript of zebrafish is maternally supplied and distributed throughout the embryo. Dev Biol 1993, 159(2):418-426.

28. Chen Y, Schier AF: Lefty proteins are long-range inhibitors of squint-mediated nodal signaling. Curr Biol 2002, I 2(24):2 2 24-2| 28.

29. Agathon A, Thisse B, Thisse C: Morpholino knock-down of antivin $I$ and antivin2 upregulates nodal signaling. Genesis 200I, 30(3): I78-182.

30. Postigo AA, Depp JL, Taylor J], Kroll KL: Regulation of Smad signaling through a differential recruitment of coactivators and corepressors by ZEB proteins. Embo J 2003, 22(10):2453-2462.

31. Postigo AA: Opposing functions of ZEB proteins in the regulation of the TGFbeta/BMP signaling pathway. Embo J 2003, 22(10):2443-2452.

32. Verschueren K, Remacle JE, Collart C, Kraft H, Baker BS, Tylzanowski P, Nelles L, Wuytens G, Su MT, Bodmer R, Smith JC, Huylebroeck D: SIPI, a novel zinc finger/homeodomain repressor, interacts with Smad proteins and binds to 5'-CACCT sequences in candidate target genes. J Biol Chem 1999, 274(29):20489-20498.

33. Nitta KR, Tanegashima K, Takahashi S, Asashima M: XSIPI is essential for early neural gene expression and neural differentiation by suppression of BMP signaling. Dev Biol 2004, 275(I):258-267.

34. Comijn J, Berx G, Vermassen P, Verschueren K, van Grunsven L, Bruyneel E, Mareel M, Huylebroeck D, van Roy F: The two-handed E box binding zinc finger protein SIPI downregulates E-cadherin and induces invasion. Mol Cell 200I, 7(6): I267-I278.
Publish with Bio Med Central and every scientist can read your work free of charge

"BioMed Central will be the most significant development for disseminating the results of biomedical research in our lifetime. "

Sir Paul Nurse, Cancer Research UK

Your research papers will be:

- available free of charge to the entire biomedical community

- peer reviewed and published immediately upon acceptance

- cited in PubMed and archived on PubMed Central

- yours - you keep the copyright
BioMedcentral 